\title{
A “JURÍSTICA” DE HENRI LÉVY-BRUHL E A CONSTRUÇÃO DOS ESTUDOS SOCIOJURÍDICOS NA FRANÇA
}

\author{
HENRI LÉVY-BRUHL'S "JURISTIC" AND THE CONSTRUCTION OF SOCIO-LEGAL \\ STUDIES IN FRANCE
}

\author{
Orlando Villas Bôas Filho \\ Doutor em Direito - USP. \\ Pós-Doutor - Université de Paris X, Nanterre. \\ Pós-Doutor - École Normale Supérieure de Paris. \\ Professor dos Programas de Pós-Graduação - Mestrado e Doutorado em Direito - e dos Cursos de \\ Graduação em Direito da FD/USP e da FD/UPM. \\ ovbf@usp.br
}

\begin{abstract}
Resumo: O objetivo deste artigo é analisar a "jurística" proposta por Henri Lévy-Bruhl, enfatizando, especialmente, sua contribuição ao desenvolvimento dos estudos sociojurídicos como campo privilegiado para a realização da pesquisa interdisciplinar. Para tanto, em primeiro lugar, a partir da revisão bibliográfica de sua obra e da literatura a ela concernida, procura situar o autor no contexto da recepção da sociologia do direito nas Faculdades de Direito francesas. Feito isso, realiza uma breve digressão relativamente à influência sobre ele exercida pelo pensamento de Émile Durkheim. Em seguida, enfoca a contribuição da "jurística" para a construção da pesquisa interdisciplinar acerca do direito na França mediante a indicação de seus paralelos com as propostas de Antoine Bailleux, Hugues Dumont e André-Jean Arnaud. Por fim, à guisa de conclusão, veicula uma breve síntese da temática analisada, enfatizando o seu potencial para a promoção da pesquisa interdisciplinar.
\end{abstract}

Palavras-chave: Jurística. Ciência do direito. Estudos Sociojurídicos. Interdisciplinaridade. Henri Lévy-Bruhl.

Abstract: This article intends to analyze the "juristic" proposed by Henri Lévy-Bruhl, emphasizing, particularly, its contribution to the development of socio-legal studies as a privileged field for the accomplishment of interdisciplinary research. To this end, based on the bibliographical review of his work and the literature concerned, it seeks first, to situate the author in the context of the reception of the sociology of law at the French Faculties of Law. Having done this, it makes a brief digression on the influence upon him of the thought of Emile Durkheim. It then focuses on the contribution of the "juristic" to the construction of interdisciplinary research on law in France by indicating its parallels with the proposals of Antoine Bailleux, Hugues Dumont and André-Jean Arnaud. Finally, by way of conclusion, it presents a brief synthesis of the thematic analyzed, emphasizing its potential for the promotion of interdisciplinary research.

Keywords: Juristic. Science of law. Socio-legal Studies. Interdisciplinarity. Henri Lévy-Bruhl.

\section{Para citar este artigo}

ABNT NBR 6023:2018

VILLAS BÔAS FILHO, Orlando. A "jurística” de Henri Lévy-Bruhl e a construção dos estudos sociojurídicos na França. Prisma Jurídico, São Paulo, v. 19, n. 1, p. 23-39, jan./jun. 2020. http://doi.org/10.5585/prismaj.v19n1.14766. 


\section{Introdução}

É possível afirmar que a atenção dispensada pelos sociólogos franceses ao direito remonta ao fim do século XIX, contexto em que autores como Émile Durkheim propunham utilizar as regras do direito como instrumento privilegiado de observação das formas de solidariedade social. ${ }^{1}$ Por outro lado, nessa mesma época, alguns professores de direito, como Léon Duguit, já manifestavam evidente interesse pela abordagem sociológica. ${ }^{2}$ Assim, segundo Soubiran-Paillet (1997 e 2000), observar-se-ia, desde então, uma significativa rivalidade entre juristas e sociólogos franceses tanto pelo monopólio da competência de elaboração e ensino de uma "ciência social" como pela apropriação da "matéria jurídica" como objeto de conhecimento, ${ }^{3}$ o que teria afetado negativamente a disseminação das ciências sociais no campo dos estudos jurídicos na França.

Referindo-se especificamente à sociologia jurídica, Carbonnier (2004 [1978]) ressalta, preliminarmente, sua lenta penetração nas Faculdades de Direito e, ademais, sua recepção assistemática e, portanto, distante da assimilação de um corpus de ensinamentos especializado. Além disso, segundo o autor, a sociologia jurídica teria sido recepcionada pelo que ele designa de disciplinas "colaterais" ou "auxiliares", tais como o direito comparado e a história do direito, ambas acostumadas com o método comparativo e portadoras de uma compreensão acerca do direito em meio à qual eram sublinhadas a relatividade e a mutabilidade. ${ }^{4}$ Por esse motivo, Arnaud (1981) destaca o caráter não ocasional da introdução da sociologia jurídica nas Faculdades de Direito francesas, por intermédio dos estudos históricos nelas desenvolvidos. ${ }^{5}$

Nesse contexto, a obra e a trajetória acadêmica de Henri Lévy-Bruhl mostram-se particularmente significativas para o desenvolvimento e a institucionalização da sociologia jurídica nas Faculdades de Direito francesas. ${ }^{6}$ Conjugando formação interdisciplinar com profunda erudição, Henri Lévy-Bruhl desenvolveu atividades acadêmicas em diversas

\footnotetext{
${ }^{1}$ Como é sabido, Durkheim (2007 [1893]) enfoca o direito como um plano privilegiado de observação da vida social, na medida em que lhe atribui o estatuto de indicador dos estados da consciência coletiva. A respeito, ver, por exemplo: Arnaud (1981), Chazel (1991), Hunt (1978), Isambert (1991), Lascoumes (1991), Massella (2014), Schluchter (2006), Serverin (2000) e Villas Bôas Filho (2010, 2017a e 2017b).

${ }^{2}$ Soubiran-Paillet (2000) aponta as tensões entre Duguit, contemporâneo de Durkheim na Universidade de Bordeaux, e os durkheimianos.

${ }^{3}$ A respeito, ver também: Serverin (2000).

${ }^{4}$ Carbonnier (2001 [1969], p. 12) afirma que "Henri Lévy-Bruhl plaçait sous le patronage d'Héraclite l'affirmation de principe que toutes règles de droit ont un caractère essentiellement provisoire et relatif".

${ }^{5}$ Segundo Arnaud (1981, p. 144), “ce n'est pas un hasard si la sociologie juridique a réellement pénétré, en France, dans les Facultés de droit, par la petite porte, celle de l'histoire. Ouverte de bonne heure à l'étude comparative dans le temps comme dans l'espace".

${ }^{6}$ A respeito, Arnaud (1981, p. 62) afirma que "le fils de Lucien Lévy-Bruhl, Henri, régna sur la sociologie du Droit française de 1926 jusqu'à sa mort, en 1964". Sobre a importância de Henri Lévy-Bruhl no pensamento jurídico francês, ver também: Carbonnier (2004 [1978]), Serverin (2000) e Soubiran-Paillet (2000).
} 
instituições, entre as quais destacam-se, conforme Soubiran-Paillet (2000), García Villegas (2015) e García Villegas e Lejeune (2011), o Centre d'Études Sociologiques, onde foi colega de Georges Gurvitch e Gabriel Le Bras, a Université de Paris e a École Pratique des Hautes Études (EPHE). Ademais, integrou o comitê editorial de prestigiosas revistas. Entre elas evidenciam-se as seguintes: Cahiers Internationaux de Sociologie; Revue Française de Sociologie e L'Année Sociologique. Vale notar, por fim, que Henri Lévy-Bruhl fundou o Laboratoire de sociologie criminelle et juridique, do qual, posteriormente, derivou o Laboratoire de sociologie juridique, dirigido, entre outros, por Jean Carbonnier, Georges Levasseur e François Terré. ${ }^{7}$

Também não se pode desconsiderar que, proveniente de uma progenitura prestigiosa, Henri Lévy-Bruhl ligava-se diretamente à ascendência intelectual de Émile Durkheim. ${ }^{8}$ A respeito, não é despiciendo notar que seu pai, Lucien Lévy-Bruhl, manteve interlocução direta (embora, por vezes, divergente) com o autor de Les formes élémentaires de la vie réligieuse. ${ }^{9}$ Como enfatiza Soubiran-Paillet (2000), a influência do pensamento de Durkheim transparece claramente na proposta de criação daquilo que Henri Lévy-Bruhl acreditava ser uma "verdadeira ciência dos fenômenos jurídicos", a "jurística", que, a despeito de não ter recebido uma acolhida mais significativa pela posteridade, ${ }^{10}$ consigna uma expressiva crítica ao dogmatismo e a uma notável contribuição ao desenvolvimento dos "estudos sociojurídicos".

Quanto a esse respeito, cumpre notar que, como destacam Arnaud e Fariñas Dulce (1998), os "estudos sociojurídicos" consistiriam em um campo de pesquisa interdisciplinar. Segundo os autores, esse campo constitui um âmbito que congrega as investigações de pesquisadores provenientes de distintas formações disciplinares. Asseveram, ademais, que a "descoberta" do "território" recoberto por esses estudos é balizada pela perspectiva do pesquisador, tendo em conta o local em que este, como observador, se situa. Por fim, sustentam a possibilidade de que esse "território" possa ser considerado cientificamente como um "campo" (champ) no sentido em que as ciências sociais o definem. ${ }^{11}$ Assumindo essas

\footnotetext{
7 A respeito, ver, especialmente: Arnaud (1998), Arnaud e Noreau (1998), García Villegas (2015) e García Villegas e Lejeune (2011).

${ }^{8}$ Cf. Arnaud (1981), Soubiran-Paillet (1997 e 2000) e Serverin (2000).

9 Carbonnier (2004 [1978]) sublinha essa questão. Para uma profunda análise do pensamento de Lucien Lévy-Bruhl, inclusive a partir de um contraste com o de Durkheim, ver, por exemplo: Keck (2008).

${ }^{10}$ Vale notar que Arnaud (1981, p. 150), referindo-se a Henri Lévy-Bruhl e à jurística, afirma que esta última "lui doit tout, à lui seul, et ne lui aura peut-être pas survécu".

${ }^{11}$ No que tange a essa última hipótese, nota-se a evidente a influência do pensamento de Bourdieu (1986) sobre os autores. Aliás, Arnaud e Fariñas Dulce (1998), ao qualificarem os "estudos sociojurídicos" como um "champ ouvert", fazem alusão à noção de campo proposta por Bourdieu. Acerca da noção de "campo" em Arnaud e em Bourdieu, ver, por exemplo, Villas Bôas Filho (2019c).
} 
hipóteses como premissas na configuração desse gênero de estudos, Arnaud e Fariñas Dulce (1998) salientam a interdisciplinaridade como sua característica fundamental.

O presente artigo, considerando a importância da obra de Henri Lévy-Bruhl no cenário intelectual francófono, pretende enfocar a sua contribuição para o desenvolvimento dos "estudos sociojurídicos", pois parte da hipótese de que, malgrado a sua limitada acolhida pela posteridade, a "jurística" propugnada pelo autor constituiria um expressivo contributo para a pesquisa interdisciplinar. A justificativa para tal empreitada decorre da escassez de trabalhos que, no Brasil, analisem o impulso da "jurística" para a constituição dos "estudos sociojurídicos" como um campo interdisciplinar. Essa situação parece decorrer, fundamentalmente, do relativo ostracismo experimentado pela empreitada teórica de Henri Lévy-Bruhl. Como bem observa Soubiran-Paillet (2000), em virtude de sua diminuta recepção pelo debate acadêmico que a sucedeu, a "jurística" não teria se constituído em um modelo para a sociologia do direito. ${ }^{12}$ Contudo, no bojo da hipótese aqui esboçada, cabe questionar se a "jurística", mesmo com os limites que lhe são inerentes, não poderia ser considerada um modelo para a pesquisa interdisciplinar.

Diante disso, a partir do exame genético da obra de Henri Lévy-Bruhl e mediante a revisão bibliográfica da literatura que a recepciona, pretende-se analisar a "jurística" proposta pelo autor, enfatizando, especialmente, sua contribuição ao desenvolvimento dos "estudos sociojurídicos" como campo privilegiado para a realização da pesquisa interdisciplinar. ${ }^{13}$ Para tanto, em primeiro lugar, procura situar o autor no contexto da recepção da sociologia do direito nas Faculdades de Direito francesas. Feito isso, realiza uma breve digressão relativamente à influência sobre ele exercida pelo pensamento de Émile Durkheim. Em seguida, enfoca a contribuição da "jurística" para a construção da pesquisa interdisciplinar acerca do direito na França mediante a indicação de seus paralelos com as propostas de Antoine Bailleux, Hugues Dumont e André-Jean Arnaud. Por fim, à guisa de conclusão, veicula uma breve síntese da temática analisada.

12 Soubiran-Paillet (2000, p. 129) enfatiza que “[la] juristique est aujourd'hui plus ou moins tombée dans l'oubli, même si l'on en fait exceptionnellement état parfois. En tout cas, elle n'a pas servi de modèle aux recherches de sociologie du droit"

13 Acerca da influência de Lévy-Bruhl no campo da antropologia jurídica, ver: Le Roy (1990), Rouland (1988 e 1995) e Vanderlinden (1996). No que tange à sociologia jurídica, ver: Arnaud (1981), Carbonnier (2004 [1978]), García Villegas (2015), García Villegas e Lejeune (2011), Soubiran-Paillet (1997 e 2000), Serverin (2000) e Van Houtte (1986). Relativamente à sua influência na história do direito e na sociologia jurídica, ver: Soula (2015). 


\section{A inscrição de Henri Lévy-Bruhl e a recepção da sociologia nas Faculdades de Direito na França}

Segundo Arnaud (1981), a sociologia jurídica teria sido recepcionada, nas Faculdades de Direito francesas, pela "pequena porta" entreaberta dos estudos históricos nelas desenvolvidos, uma vez que estes, renunciando às metodologias tradicionais, já se mostravam interessadas, desde o final do século XIX, pelas descobertas etnológicas e antropológicas que se desenvolviam em clara afinidade com a sociologia. ${ }^{14}$ Esses estudos, afastando-se do dogmatismo convencional, procuravam compreender o direito a partir de seus aspectos institucionais e sociais, o que, evidentemente, os tornava particularmente receptivos às pesquisas desenvolvidas pela sociologia, especialmente a de matriz durkheimiana, que concebia o direito como um "fato social" capaz de "revelar" a natureza íntima de determinado grupo social. ${ }^{15}$

Como ressaltam Serverin (2000) e Soubiran-Paillet (1997 e 2000), é certo que alguns juristas expressivos, como Léon Duguit e Maurice Hauriou, ao integrarem conhecimentos considerados "sociológicos" em seus ensinamentos, teriam se afastado de maneira sistemática do modo como Durkheim concebia as instituições jurídicas. Apesar disso, não é possível desconsiderar as reverberações das teses do grande sociólogo francês em diversos juristas, tanto entre os que foram seus contemporâneos como entre os que pertenceram a gerações posteriores. ${ }^{16}$ Como se sabe, o pensamento de Durkheim experimentou ampla difusão e influenciou diversos autores proeminentes, tais como Marcel Mauss, Lucien Lévy-Bruhl, Maurice Halbwachs, Célestin Bouglé, Henri Hubert, François Simiand e Georges Davy. ${ }^{17}$ Conforme observam André-Jean Arnaud e Pierre Noreau (1998), trata-se de uma verdadeira escola que teria ostentado uma posição hegemônica na sociologia acadêmica francesa até pelo menos a Segunda Guerra Mundial, a partir da qual começa a ceder espaço para outros modelos interpretativos. ${ }^{18}$ Como se verá a seguir, as ideias de Durkheim influenciaram profundamente a "jurística" de Henri Lévy-Bruhl. ${ }^{19}$

${ }^{14}$ Como enfatiza Arnaud (1981, p. 62) “c'est largement par l'intermédiaire des historiens juristes [...] que la sociologie s'est introduite chez les civilistes".

15 Acerca dessa questão, ver, por exemplo: Arnaud (1981), Hunt (1978), Isambert (1991), Lascoumes (1991), Massella (2014), Schluchter (2006), Serverin (2000), Steiner (2005) e Villas Bôas Filho (2010, 2017a e 2017b).

${ }^{16}$ Vale lembrar que diversos interlocutores de Durkheim eram importantes juristas, tais como Léon Duguit, Maurice Hauriou, François Gény, Édouard Lambert e Raymond Saleilles. Além disso, Durkheim entabulou importantes controvérsias com Gabriel Tarde e Joseph Barthélemy. Por fim, encarregou-se, com Paul Fauconnet, de duas rubricas de L'Année sociologique nas quais eram resenhadas e comentadas obras jurídicas com interesse para a sociologia de época.

17 Steiner (2005) consigna um elucidativo diagrama dos principais interlocutores de Durkheim na revista L'Année Sociologique entre 1898 e 1913. No que concerne à influência de Durkheim na sociologia jurídica, ver, por exemplo: Arnaud (1998), Arnaud e Noreau (1998), Serverin (2000) e Soubiran-Paillet (2000).

${ }^{18}$ No mesmo sentido, ver: Arnaud (1998). Para uma análise da "escola francesa de sociologia", ver, por exemplo: Arnaud (1981), Berthelot (2008) e Cuin e Gresle (2017a e 2017b). Valade (2008), entretanto, considera que o termo "escola" seria 
Situado no interior da historiografia jurídica francesa, o futuro criador da "jurística" contribuiu decisivamente para a efetiva introdução da sociologia jurídica nas Faculdades de Direito de seu país. ${ }^{20}$ A esse respeito, Arnaud (1981) aponta a existência de duas gerações de historiadores do direito entre o fim do século XIX e meados do século XX. Conforme o autor, a primeira delas foi constituída, entre outros, por expressivos autores como Paul Huvelin e Paul Frédéric Girard. A segunda teve como figuras centrais Henri Lévy-Bruhl e Gabriel Le Bras. ${ }^{21}$ Não se trata, portanto, de um autor qualquer, e sim de um dos mais expressivos expoentes da segunda geração de historiadores do direito na França.

Ademais, vale notar que, como observa Soubiran-Paillet (2000), Henri Lévy-Bruhl teve uma formação pouco usual aos juristas de sua época, uma vez que, além da Faculdade de Direito, cursou a École Pratique des Hautes Études. Esse aspecto certamente contribuiu para sua abertura às ciências sociais, pois, entre outras coisas, permitiu-lhe manter interlocução com grandes teóricos da sociologia e da etnologia de sua época. ${ }^{22}$ A propósito, o diálogo de Henri Lévy-Bruhl com Marcel Mauss é particularmente ilustrativo do quanto o pensamento do autor da "jurística" beneficiou-se de aportes das ciências sociais. Conforme ressalta Arnaud (1981), em carta datada de meados dos anos 1930, Marcel Mauss, respondendo a Henri Lévy-Bruhl, enfatizava a necessidade de abordagem do direito a partir de seu enraizamento no tecido social, e não em termos de abstrações dogmáticas. ${ }^{23}$

\section{Henri Lévy-Bruhl e a tradição durkheimiana}

A influência de Émile Durkheim faz-se notar claramente na concepção de Lévy-Bruhl (1950 e 2000 [1961]) acerca do que seria uma abordagem verdadeiramente científica do

impróprio para qualificar a produção sociológica francesa da época de Durkheim. Segundo o autor, nesse contexto, seria observável o confronto de três grupos distintos: a) o antropológico e etnográfico (P. Broca e C. Letourneau); b) o criminológico (A. Lacassagne e G. Tarde); c) o universitário (É. Durkheim, G. Espinas, A. Fouillée e G. Richard). Para um excelente contraste dos pensamentos de Durkheim e de Weber, ver: Boudon (1998).

${ }^{19}$ Sobre a influência de Durkheim em Henri Lévy-Bruhl, ver: Villas Bôas Filho (2019b). Note-se que expressivos juristas, como Emmanuel Lévy, Paul Huvelin e Joseph Charmont, foram inspirados por Durkheim e, inclusive, colaboraram na revista L'Année Sociologique.

${ }^{20}$ A respeito, ver também: Carbonnier (2004 [1978]), Serverin (2000) e Soubiran-Paillet (2000).

21 Arnaud (1981) e Soubiran-Paillet (2000) ressaltam a importância de Henri Lévy-Bruhl e Gabriel Le Bras entre os historiadores do direito na França após a Segunda Guerra, ressaltando sua vinculação a uma tradição que remonta a Lucien Lévy-Bruhl, Paul Huvelin, Célestin Bouglé, François Simiand e Marcel Mauss. No que concerne especificamente à proximidade do autor com François Simiand, ver: Soubiran-Paillet (2000).

${ }^{22}$ No que tange à etnologia jurídica, Rouland (1988, p. 111) afirma que "elle ne commence véritablement à naître qu'avec H. Lévy-Bruhl (1884-1964), dont les élèves (M. Alliot, J. Poirier) surent faire fructifier les enseignements.” Por esse motivo, Rouland (1995, p. 11) sustenta que "le véritable père de l'ethnologie juridique française est H. Lévy-Bruhl". Cumpre notar que Alliot (1968), por exemplo, destaca a influência exercida sobre ele por H. Lévy-Bruhl. Por fim, vale mencionar a expressiva apresentação geral da etnologia jurídica realizada por Lévy-Bruhl (1968).

23 A respeito, como enfatiza Arnaud (1981, p. 146), Marcel Mauss, dirigindo-se a Henri Lévy-Bruhl, declarava que "les choses du droit, comme les choses du mythe, doivent être prises dans l'ensemble, dans le tissu dont elles font partie et non pas abstraitement. [...]". 
direito, por ele designada de "jurística" (juristique). ${ }^{24}$ Desde logo, vale observar que, ao analisar as "origens da ciência do direito", após referir-se a autores como Montesquieu, SaintSimon, Comte, Marx, Engels e Spencer, por ele considerados precursores dessa forma de abordagem, Lévy-Bruhl (2000 [1961]) atribui a Durkheim um papel de destaque na "constituição de uma ciência do direito", pois o considera responsável por fixar definitivamente as relações entre as perspectivas jurídica e sociológica, de modo a reconhecer e discernir a natureza eminentemente social do direito. Consequentemente, segundo LévyBruhl (2000 [1961]), a concepção durkheimiana proporcionaria a possibilidade de enfocar o direito como uma manifestação da vida social, tal como outras dimensões que a constituem, como a linguagem, a arte, a religião, com as quais manteria estreita relação.

De fato, como é sabido, Durkheim (2007 [1893]) enfoca o direito como um plano privilegiado de observação da vida social, na medida em que o considera o "símbolo visível" das formas de solidariedade social. Isso ocorre porque, segundo o autor, o direito, ao codificar as regras imperativas da vida social, reproduziria as formas fundamentais que expressam a solidariedade. Nesse sentido, o argumento de Durkheim é de que o direito, como "regra de conduta sancionada", variaria conforme as relações sociais por ele reguladas, prestando-se, assim, a figurar como "indicador" da forma de solidariedade social vigente em uma dada sociedade em um momento determinado. Assim, como observa Lenoir (1994), Durkheim recorre ao direito em caráter não meramente ocasional, e sim como uma estratégia que resulta diretamente da própria construção de seu objeto de pesquisa. ${ }^{25}$

Por esse motivo, para Lévy-Bruhl (2000 [1961]) a obra de Durkheim teria reorientado as pesquisas jurídicas, impondo-lhes a obrigação de estudar o meio social para, a partir dele, verificar se, e em que medida, a norma jurídica seria aplicada, as razões de seu aparecimento, de sua eficácia ou de seu desuso. Tratava-se, assim, de assumir, em estreita consonância com as ideias expressas em De la division du travail social e Les règles de la méthode sociologique, que o direito seria uma "coisa social". Aliás, na perspectiva do autor, seria justamente isso que permitiria sua apreensão por uma "ciência dos fenômenos jurídicos". ${ }^{26}$ Por esse motivo, segundo Lévy-Bruhl (2000 [1961]), diversos juristas contemporâneos de Durkheim, especialmente Emmanuel Lévy, Paul Huvelin e Joseph Charmont, teriam sido por

\footnotetext{
${ }^{24}$ Lévy-Bruhl (1950, p. 128) propõe a utilização do termo "jurística" (juristique) para nominar o que considerava ser uma abordagem científica do direito. Segundo ele, a expressão "ciência do direito" seria equívoca e os termos "nomologia" (nomologie) e "temistologia" (thémistologie) seriam pedantes. Sobre essa questão, ver: Arnaud (1981).

${ }^{25}$ No mesmo sentido, ver: Steiner (2005).

${ }^{26}$ Influenciado por Durkheim, Lévy-Bruhl (1950, p. 126) afirmava expressamente que "le droit est chose sociale [...]".
} 
ele inspirados e, inclusive, colaborado na revista L'Année Sociologique. ${ }^{27}$ Ademais, como notam García Villegas e Lejeune (2011), mesmo Henri Lévy-Bruhl, em virtude de sua adesão às teses de Durkheim, teria progressivamente se distanciado de Georges Gurvitch que, como se sabe, se opunha ao fundador da sociologia científica na França, entre outras coisas, por considerar excessiva a importância por ele atribuída aos juristas. ${ }^{28}$

Não há como realizar aqui uma incursão mais profunda no tratamento dado por Durkheim ao direito no bojo de sua sociologia. Uma empreitada como essa demandaria digressões incompatíveis, inclusive em extensão, com o propósito da presente análise, cujo escopo consiste apenas em sublinhar a contribuição da obra de Henri Lévy-Bruhl para o desenvolvimento dos "estudos sociojurídicos". Logo, para os objetivos deste artigo, importa notar que, em estreita consonância com o pensamento de Durkheim (2007 [1893] e 2010 [1895]), Lévy-Bruhl (1950 e 2000[1961]) sustentava que todo aquele que pretendesse desenvolver o que ele designava de "jurística" não poderia jamais desconsiderar o caráter social dos fatos jurídicos e as ligações por eles mantidas com outros fatos sociais. ${ }^{29}$

\section{A "jurística" e a construção da pesquisa interdisciplinar acerca do direito na França: as "afinidades" da proposta de Henri Lévy-Bruhl com as de André-Jean Arnaud, Antoine Bailleux e Hugues Dumont}

Segundo Serverin (2000), a tradição acadêmica que propunha a necessidade de o ensino do direito contemplar informações sobre os fatos sociais teria encontrado em Henri Lévy-Bruhl um de seus mais expressivos epígonos. Como ressalta Arnaud (1981), uma das preocupações fundamentais do autor consistia em perscrutar as condições de existência de uma "ciência do direito". ${ }^{30}$ Em seu entendimento, uma abordagem científica das "regras jurídicas" (règles du droit) seria possível desde que devidamente submetida a uma metodologia rigorosa que as considerasse como "fatos sociais" que, em virtude de sua natureza particular, deveriam ser "isolados" de outros fatos congêneres que, entretanto, não teriam qualidade jurídica. Assim, como experimentariam as mesmas variações dos demais "fatos sociais", as "regras jurídicas" deveriam ser objeto de uma análise regida pelo método

${ }^{27}$ Lévy-Bruhl (2000 [1961]) também menciona a influência, ainda que indireta, de Durkheim sobre Maurice Hauriou e Léon Duguit.

${ }^{28}$ De todo modo, não se pode desprezar a desconstrução que Durkheim (2007 [1893]) realiza das categorias jurídicas. Sobre a relação de Henri Lévy-Bruhl e Georges Gurvitch, ver especialmente: Arnaud (2012), Commaille (2007) e García Villegas (2015). A respeito, ver também: Goyard-Fabre (2007).

${ }^{29}$ Vale notar que o autor da "jurística" também se vale de diversas teses de Durkheim. Lévy-Bruhl (1964), por exemplo, corrobora a definição durkheimiana de crime. A respeito, ver, especialmente: Durkheim (1899/1900).

${ }^{30}$ Quanto a essa questão, Arnaud (1981, p. 150), citando diretamente Lévy-Bruhl, afirma que "'est-il permis de donner au droit le nom de science' demandait-il. Et, résumant sa position sur ce point, de répondre que les règles de droit 'obéissent à un certain déterminisme qui, pour être moins rigide que celui des phénomènes physiques ou biologiques, n'en est pas moins réel. Il ressort de là qu'elles peuvent être objet de science'”. 
que orienta as demais ciências sociais: observação e interpretação. A partir dessas balizas, o autor delineia o que designa de "jurística".31

Desde logo, é possível notar que as características gerais atribuídas por Lévy-Bruhl (1950 e 2000 [1961]) à "jurística", entendida como uma "verdadeira ciência do direito", exprimem claramente a influência sobre ele exercida pela obra de Émile Durkheim. ${ }^{32}$ Como observam Serverin (2000) e Soubiran-Paillet (2000), para Henri Lévy-Bruhl o desenvolvimento da "jurística" implicava a imprescindível consideração da sociologia por parte dos juristas. ${ }^{33}$ Logo, a partir de uma assertiva de forte acento durkheimiano, Lévy-Bruhl (1950) sustentava que a assunção de uma abordagem sociológica permitiria aos juristas a tomada de consciência de que "os fenômenos sociais teriam causas sociais" e que, sendo o direito um "fato social por excelência", ele revelaria a "natureza íntima do grupo". ${ }^{34}$ Desse modo, compreendido a partir de seu enraizamento social, o direito tornar-se-ia passível de uma apreensão objetiva e, enquanto tal, científica. ${ }^{35}$

Conforme ressalta Arnaud (1981), Henri Lévy-Bruhl considerava que o objeto da "jurística" seria o "direito vivo" (le droit vivant) e o método por ela preconizado, consonante com o utilizado nas ciências sociais em geral, consistiria, basicamente, conforme mencionado, na mobilização de duas operações: a observação e a interpretação. ${ }^{36}$ A observação permitiria apontar os seguintes traços característicos do direito: a) ele seria composto por um conjunto de regras obrigatórias; b) tais regras seriam impostas por determinado grupo social; c) as regras constitutivas desse conjunto seriam passíveis de constante modificação. Para Arnaud (1981), derivaria daí uma visão pluralista do direito, pois, segundo ele, na perspectiva de Henri Lévy-Bruhl, o Estado não seria o único agrupamento social do qual emanariam as regras jurídicas. Portanto, existiriam regras supraestatais e infraestatais. Ademais, na medida em que concebe a vontade coletiva como a fonte do direito, seria possível reputar como jurídicas até mesmo práticas estabelecidas como ilegais pelo direito positivo. ${ }^{37}$ Aliás, decorreria também da visão de Lévy-Bruhl a possibilidade de sustentar a existência da

\footnotetext{
31 Vale notar que Lévy-Bruhl (1950) designa de "juristicien" o pesquisador que desenvolve o tipo de estudo por ele preconizado. Para excelentes análises sintéticas da "jurística" em Henri Lévy-Bruhl, ver, por exemplo: Arnaud (1981) e Serverin (2000). Para uma discussão mais recente da "jurística", ver, por exemplo: Puzhaev (2017) e Villas Bôas Filho (2019b).

32 Referindo-se à "jurística" de Henri Lévy-Bruhl, Serverin (2000) afirma que "hommage est rendu à Durkheim et à son école, pour avoir 'montré la nature éminemment sociale du droit'".

${ }^{33}$ A respeito, ver, por exemplo: Arnaud (1981), García Villegas e Lejeune (2011) e Soubiran-Paillet (2000).

${ }^{34}$ Segundo Lévy-Bruhl (1950, p. 126), "le droit est le fait social par excellence. Plus que la religion, plus que le langage, plus que l'art, il révèle la nature intime du groupe. Pour qui veut connaître une collectivité, le premier ordre de documents qu'il devra consulter, ce seront ses lois, ou, plus exactement [...], la manière dont ses lois sont appliquées".

${ }^{35}$ A respeito, para uma análise que compara Henri Lévy-Bruhl e Léon Duguit, ver: Commaille (2015).

${ }^{36}$ Sobre a questão do método, ver Lévy-Bruhl (2000 [1961]).

37 A respeito, Arnaud (1981, p. 151) assevera que "selon cette conception, on pourrait en arriver à considérer même des pratiques positivement illégales, comme des éléments de droit d'une société".
} 
derrogação, pelo costume, de um direito em vigor que se afigurasse contrário às necessidades e anseios sociais. ${ }^{38}$

Ora, é justamente porque o direito seria uma "coisa viva" (chose vivante), dependente de fatores perfeitamente observáveis e, de certo modo, "calculáveis", que uma verdadeira "ciência do direito" - por ele designada de "jurística" - afigurar-se-ia viável. Nessa perspectiva, a "jurística" restituiria ao estudo do direito a dimensão social que as abordagens dogmáticas dele haviam excluído. Conforme sublinha Soubiran-Paillet (2000), o método propugnado por Henri Lévy-Bruhl partia dos estudos jurídicos para abrir-se a outras disciplinas das ciências sociais, especialmente a história e a sociologia. ${ }^{39}$ Aliás, Carbonnier (2004 [1978]) enfatiza que a "jurística” teria a pretensão de conjugar a sociologia jurídica, a história do direito e o direito comparado para contrastar-se com a "ciência tradicional do direito", ou com a "dogmática jurídica”, fundada num método dedutivo. Assim, a "jurística", mobilizando equilibradamente as três disciplinas mencionadas, teria por base o emprego da indução do método comparativo.

Quanto a esse aspecto, vale ressaltar que, após propugnar que a "jurística" consistiria no estudo dos "fatos jurídicos" considerados neles mesmos, sem preocupação prática, LévyBruhl (1950 e 2000 [1961]) afirmava que as "instituições", em seus mais diversos aspectos, constituiriam seu objeto fundamental de análise. ${ }^{40}$ Ressaltava, também, que uma empreitada como essa demandaria necessariamente a assunção de uma metodologia interdisciplinar capaz de articular a perspectiva jurídica com a histórica, a comparativa e a sociológica. Nesse sentido, é possível sustentar que a interdisciplinaridade que caracteriza a proposta de LévyBruhl (1950 e 2000 [1961]) reverbera nos "estudos sociojurídicos" contemporâneos da França, ainda que estes, evidentemente, a desenvolvam em um nível de maior profundidade e sofisticação.

Dumont e Bailleux (2010), por exemplo, enfatizando os aportes indispensáveis das ciências sociais para a compreensão do fenômeno jurídico, propõem o que denominam de "esboço de uma teoria das aberturas interdisciplinares acessíveis aos juristas”. Assim, procurando abordar a possibilidade de uma abertura interdisciplinar realista, os autores realçam a importância de os juristas utilizarem estudos desenvolvidos na antropologia, na filosofia, na história, na ciência política e na sociologia para o enriquecimento de suas

\footnotetext{
${ }^{38}$ Sobre essa questão, ver: Lévy-Bruhl (2000 [1961]).

${ }^{39}$ Conforme Soubiran-Paillet (2000, p. 127), o método proposto por Henri Lévy-Bruhl, "part du droit (le chercheur ici sera d'abord et avant tout un juriste), pour aller vers d'autres disciplines [...]."

40 A respeito, Arnaud (1981, p. 151) ressalta que "l'objet de la juristique est constitué par l'étude des faits juridiques considérés en eux-mêmes, et sans préoccupation pratique. Plus qu'aux systèmes de droit, le juristicien s'intéressera aux institutions, et utilisera une méthode 'à la fois juridique, historique, comparative et sociologique".
} 
próprias análises. Ressaltam, entretanto, que essa apropriação não implica supor que os juristas farão, eles próprios, estudos de maior relevância no âmbito das diversas disciplinas das quais se apropriam. ${ }^{41}$

É nesse sentido que, pretendendo esboçar uma "ciência interdisciplinar e crítica do direito", Dumont e Bailleux (2010) procuram distinguir três "círculos concêntricos": direito, como objeto de estudo; doutrina jurídica; e ciência do direito. ${ }^{42}$ Não se trata aqui de reconstruir a perspectiva dos autores, mas apenas de sublinhar o quanto a "ciência do direito", por eles proposta como expressão do terceiro "círculo concêntrico", que abrange os dois primeiros, é tributária de uma perspectiva interdisciplinar que apresenta claros paralelos com relação à "jurística” de Henri Lévy-Bruhl. Tal como esse autor, Dumont e Bailleux (2010) propõem uma "ciência do direito" que - em oposição a uma visão monodisciplinar que qualificam de "positivista - tem a pretensão de assumir uma metodologia crítica e interdisciplinar. $^{43}$

Analogamente, Arnaud (1988 e 1998) propõe a constituição de um "carrefour interdisciplinaire" para o estudo do direito, cujo escopo consistiria na promoção da pesquisa interdisciplinar mediante a construção de uma linguagem comum, sobre um mesmo objeto e com um propósito também comum. ${ }^{44}$ Segundo Arnaud (1992), os "estudos sociojurídicos" seriam o local privilegiado para a realização da pesquisa interdisciplinar de modo a possibilitar o desenvolvimento de uma pesquisa distinta da pura teorização e do dogmatismo estéril. ${ }^{45}$ Trata-se, guardados os devidos distanciamentos, de uma proposta que também apresenta afinidade com a de Henri Lévy-Bruhl, pois, tal como ela, procura afastar-se de uma análise dogmática do direito. Ademais, Arnaud (1994) sustenta que a expressão "estudos sociojurídicos" englobaria, genericamente, o conjunto dos pesquisadores interessados em uma abordagem social do direito. Os "estudos sociojurídicos" formariam, assim, um tipo de

\footnotetext{
${ }^{41}$ Nesse particular, Dumont e Bailleux (2010, p. 276-277) ressaltam que o fundamental é que o jurista consiga "comprendre et exploiter des études sociologiques, politologiques, historiques ou philosophiques, sans pour autant supposer qu'il serait capable de faire lui-même en première ligne un travail relevant de ces disciplines". Sobre a proposta dos autores, ver: Villas Bôas Filho (2018 e 2019a).

42 Segundo Dumont e Bailleux (2010, p. 277), "il consiste à distinguer trois cercles concentriques. Le premier cercle forme l'objet d'étude de ce que l'on appelle communément la doctrine. Celle-ci forme le deuxième cercle qui entoure le premier. La science du droit, troisième cercle, a pour particularité d'englober les deux premiers".

${ }^{43}$ A respeito, ver também: Bailleux e Ost (2013) e Villas Bôas Filho (2018 e 2019a).

${ }^{44}$ Referindo-se a esse projeto, Arnaud (1988, p. 7 ; e 1998, p. 77) afirma que se trata de "l'élaboration des grandes lignes d'une Théorie du droit et de la société qui permette aux juristes et aux chercheurs en sciences sociales de travailler avec un langage commun sur un objet commun et dans un but commun". Arnaud (1991) procurou introduzir essa questão na discussão brasileira mediante sua incorporação a uma coletânea de artigos que publicou em português.

45 Segundo Arnaud (1992, p. 18), "la discipline par où les chercheurs entendent précisément échapper tant à la pure théorisation qu'au dogmatisme stérile, se trouve aux confins de la politique, de la psychologie, de la sociologie et du Droit et se nomme, selon les lieux et les écoles, sociologie du Droit, sociologie juridique, Socio-legal studies, Law and Society studies, Law in context". No mesmo sentido, ver: Arnaud (2013) e Arnaud e Fariñas Dulce (1998). A respeito, ver: Villas Bôas Filho (2018).
} 
sociologia jurídica renovada, na qual as dimensões econômica e política seriam adicionadas às reivindicações realistas dos primeiros sociólogos jurídicos, entre os quais certamente figura o criador da "jurística". 46

\section{Considerações finais}

O presente artigo pretendeu analisar a "jurística" proposta por Henri Lévy-Bruhl, enfatizando, especialmente, sua contribuição ao desenvolvimento dos "estudos sociojurídicos" como campo privilegiado para a realização da pesquisa interdisciplinar. Para tanto, em primeiro lugar, procurou situar o autor no contexto da recepção da sociologia do direito nas Faculdades de Direito francesas, sublinhando seu protagonismo no âmbito da segunda geração de historiadores do direito. Assim, com base em autores como André-Jean Arnaud e Francine Soubiran-Paillet, ressaltou-se que a formação interdisciplinar de Henri Lévy Bruhl e a sua interlocução com expressivos autores das ciências sociais de seu tempo foram determinantes para ensejar sua abertura com relação a uma abordagem social do fenômeno jurídico.

Feito isso, procurou-se realizar uma breve digressão pela influência exercida pelo pensamento de Émile Durkheim sobre a obra de Henri Lévy-Bruhl. Para esse propósito, enfatizou-se, especialmente, a tese, sustentada por Durkheim no livro De la division du travail social, de que o direito constituiria um instrumento privilegiado de observação da vida social, na medida em que seria o "símbolo visível" das formas de solidariedade social para, a partir dela, explicar a razão de Henri Lévy-Bruhl considerar a obra de Durkheim como responsável pela promoção de uma reorientação das pesquisas jurídicas ${ }^{47}$ Conforme visto, a importância atribuída pelo criador da "jurística" à obra de Durkheim decorre do fato de que esta teria estabelecido a necessidade de estudar o direito a partir de uma abordagem que tem por base o seu enraizamento na sociedade. Ressaltou-se, assim, que as características gerais conferidas por Henri Lévy-Bruhl à "jurística", entendida como uma "verdadeira ciência do direito", exprimem claramente a influência sobre ele exercida pela obra de Émile Durkheim.

Em seguida, foi enfocada a contribuição da "jurística” para a construção da pesquisa interdisciplinar acerca do direito na França. Para tanto, ressaltou-se que, para Henri Lévy-

\footnotetext{
${ }^{46}$ Vale notar que Arnaud (1981, p. 153), referindo-se à obra de Henri Lévy-Bruhl, ressalta que "l'exposé paraîtra peut-être aujourd'hui un peu simpliste, tant les méthodes ont évolué. Mais nous assistons là, réellement, aux premiers pas d'une sociologie juridique véritable".

${ }^{47}$ Sobre essa tese de Durkheim, ver, entre outros: Arnaud (1981), Baechler (2011), Hunt (1978), Isambert (1991), Schluchter (2006), Serverin (2000), Steiner (2005), Terré (2011), Treves (2004), Treviño (2008) e Villas Bôas Filho (2010, 2017a, 2017b e 2019b).
} 
Bruhl, a "jurística", como estudo dos "fatos jurídicos" considerados neles mesmos e sem preocupação prática, deveria analisar as "instituições", em seus mais diversos aspectos, de modo a demandar, necessariamente, a assunção de uma metodologia interdisciplinar capaz de articular a perspectiva jurídica com a histórica, a comparativa e a sociológica. Para destacar esse caráter interdisciplinar da proposta de Henri Lévy-Bruhl e sua importância no desenvolvimento dos "estudos sociojurídicos" na França, foi realizada, em caráter ilustrativo, uma indicação de seus paralelos com a "ciência interdisciplinar e crítica do direito" propugnada por Bailleux e Dumont (2013) e com a concepção de Arnaud (1988 e 1998) a respeito dos "estudos sociojurídicos" como um "carrefour interdisciplinaire". ${ }^{48}$

Diante do exposto, é possível sustentar que, a despeito de suas limitações teóricas e metodológicas, a "jurística" constitui um modelo de pesquisa interdisciplinar cujo potencial heurístico demanda maior consideração. Em virtude de se afigurar como um instrumento crítico ao "dogmatismo estéril" e à "teorização ornamental”, a obra de Henri Lévy-Bruhl pode servir de inspiração à promoção de uma pesquisa interdisciplinar efetiva. Assim, procurando articular a perspectiva jurídica com a histórica, a comparativa e a sociológica sem, entretanto, misturar indiscriminadamente esses gêneros de análise, ${ }^{49}$ a "jurística", ainda que de forma elementar, contribui para a constituição de um campo de pesquisa jurídica que, diversamente do que ocorre com o "ecumenismo ingênuo", seja capaz de exprimir na forma do que Commaille (2016) designa de "pesquisa de complementaridades". 50

\section{Referências}

ALLIOT, M. L'acculturation juridique. In: POIRIER, Jean (dir.). Ethnologie générale. Paris: Gallimard, 1968, p. 1180-1246. (Encyclopédie de la Pléiade)

ARNAUD, A.-J. Critique de la raison juridique 1. Où va la sociologie du droit? Paris: LGDJ, 1981.

ARNAUD, A.-J. Droit et société: un carrefour interdisciplinaire. Revue Interdisciplinaire d'Études Juridiques, v. 21, p. 7-32, 1988.

${ }^{48}$ Esse paralelo ilustrativo poderia ser estendido também à sofisticada empreitada interdisciplinar proposta por Commaille (2015). Acerca da "sociologia política do direito" de Jacques Commaille, ver: Villas Bôas Filho (2015 e 2019b).

${ }^{49}$ A respeito, Caillosse (2011) alerta para os riscos de mistura indiscriminada dos gêneros de análise e para a celebração acrítica, por suas supostas virtudes intrínsecas, da hibridação metodológica. Segundo esse autor, não obstante as fronteiras disciplinares possam parecer, comumente, esclerosadas e contraproducentes, o fato é que a vontade ingênua de as abolir seria insensata na medida em que isso poderia produzir um território intelectual totalmente desestruturado e desprovido de consistência.

50 Segundo Commaille (2016), a "pesquisa de complementaridade" (recherche de complementarité) consiste em uma articulação estruturada de diversas perspectivas dirigidas à compreensão da regulação jurídica. 
ARNAUD, A.-J. O direito traído pela filosofia. Tradução Wanda de Lemos Capeller e Luciano Oliveira. Porto Alegre: Fabris, 1991.

ARNAUD, A.-J. Droit et Société: du constat à la construction d'un champ commun. Droit et Société, n. 20-21, p. 17-38, 1992.

ARNAUD, A.-J. Le droit comme produit. Présentation du dossier sur la norme de la production juridique. Droit et Société, n. 27, p. 293-301, 1994.

ARNAUD, A.-J. Le droit trahi par la sociologie. Une pratique de l'histoire. Paris: LGDJ, 1998.

ARNAUD, A.-J. Jean Carbonnier. Un juriste dans la cité. Paris: LGDJ, 2012.

ARNAUD, A.-J. ; FARIÑAS DULCE, M. J. Introduction à l'analyse sociologique des systèmes juridiques. Bruxelles: Bruylant, 1998.

ARNAUD, A.-J.; NOREAU, P. The sociology of law in France: trends and paradigms. Journal of Law and Society, v. 25, n. 2, p. 257-283, jun. 1998.

BAECHLER, J. Un chef-d'œuvre d'Émile Durkheim: de la division du travail social. In: BOUDON, R. (dir.). Durkheim fut-il durkheimien? Actes du colloque organisé les 4 et 5 novembre 2008 par l'Académie des Sciences Morales et Politiques. Paris: Armand Colin, 2011. p. 11-25.

BAILLEUX, A.; OST, F. Droit, contexte et interdisciplinarité: refondation d'une démarche. Revue Interdisciplinaire d'Études Juridiques, v. 70, n. 1, p. 25-44, 2013.

BERTHELOT, J.-M. La construction de la sociologie. 6 éd. Paris: Presses Universitaires de France, 2008.

BOUDON, R. Durkheim et Weber: convergences de méthode. In: BOUDON, R. Études sur les sociologues classiques. Paris: Presses Universitaires de France, 1998. p. 93-136.

(Quadrige.)

BOURDIEU, P. La force du droit. Éléments pour une sociologie du champ juridique. Actes de la Recherche en Sciences Sociales, Paris, v. 64, p. 3-19, Sept. 1986.

CAILLOSSE, J. La sociologie politique du droit, le droit et les juristes. Droit et Société, n. 77, p. 187-206, 2011.

CARBONNIER, J. Flexible droit: pour une sociologie du droit sans rigueur. $10^{\mathrm{e}}$ éd. Paris: LGDJ, 2001 [1969].

CARBONNIER, J. Sociologie juridique. $2^{\mathrm{e}}$ éd. Paris: Presses Universitaires de France, 2004 [1978]. (Quadrige.)

CHAZEL, F. Émile Durkheim et l'élaboration d'un 'programme de recherche en sociologie du droit'. In: CHAZEL, F.; COMMAILLE, J. (dir.). Normes juridiques et régulation sociale. Paris: LGDJ, 1991. p. 27-38. (Collection Droit et Société.) 
COMMAILLE, J. La construction d'une sociologie spécialisée. Le savoir sociologique et la sociologie juridique de Jean Carbonnier. L’Année Sociologique, v. 57, n. 2, p. 275-299, 2007.

COMMAILLE, J. À quoi nous sert le droit? Paris: Gallimard, 2015.

COMMAILLE, J. À quoi nous sert le droit pour comprendre sociologiquement les incertitudes des sociétés contemporaines? SociologieS [En ligne], Dossiers, Sociétés en mouvement, p. 1-12, 2016. Disponível em: http://sociologies.revues.org/5278. Acesso em: 7 mar. 2016.

CUIN, C.-H.; GRESLE, F. História da sociologia 1: antes de 1918. Tradução Alexandre Agabiti Fernandez. Petrópolis: Vozes, 2017a.

CUIN, C.-H.; GRESLE, F. História da sociologia 2: depois de 1918. Tradução Alexandre Agabiti Fernandez. Petrópolis: Vozes, 2017b.

DUMONT, H.; BAILLEUX, A. Esquisse d'une théorie des ouvertures interdisciplinaires accessibles aux juristes. Droit et Société, n. 75, p. 275-293, 2010.

DURKHEIM, É. Deux lois de l'évolution pénale. L'Année Sociologique, v. 4, p. 65-95, 1899-1900.

DURKHEIM, É. De la division du travail social. $7^{\mathrm{e}}$ éd. Paris: Presses Universitaires de France, 2007 [1893]. (Quadrige.)

DURKHEIM, É. Les règles de la méthode sociologique. Paris: Flammarion, 2010 [1895]. (Champs Classiques.)

GARCÍA VILLEGAS, M. Les pouvoirs du droit: analyse comparée d'études sociopolitiques du droit. Paris: LGDJ, 2015.

GARCÍA VILLEGAS, M.; LEJEUNE, A. La sociologie du droit en France: de deux sociologies à la création d'un projet pluridisciplinaire? Revue Interdisciplinaire d'Études Juridiques, v. 66, n. 1, p. 1-39, 2011.

GOYARD-FABRE, S. Re-penser la pensée du droit: les doctrines occidentales modernes au tribunal de la raison interrogative-critique. Paris: Vrin, 2007.

HUNT, A. The sociological movement in law. London: MacMillan, 1978.

ISAMBERT, F.-A. Durkheim et la sociologie des normes. In: CHAZEL, F.; COMMAILLE, J. (dir.). Normes juridiques et régulation sociale. Paris: LGDJ, 1991. p. 51-64. (Collection Droit et Société.)

KECK, F. Lévy-Bruhl: entre philosophie et anthropologie. Paris: CNRS éditions, 2008. LASCOUMES, P. Le droit comme science sociale. La place de E. Durkheim dans les débats entre juristes et sociologues à la charnière des deux derniers siècles (1870-1914). In: CHAZEL, F.; COMMAILLE, J. (dir.). Normes juridiques et régulation sociale. Paris: LGDJ, 1991. p. 39-49. (Collection Droit et Société.) 
LE ROY, É. Juristique et anthropologie: un pari sur l'avenir. Journal of Legal Pluralism and Unofficial Law, n. 29, p. 5-21, 1990.

LÉVY-BRUHL, H. La science du droit ou “juristique". Cahiers Internationaux de Sociologie, v. 8, p. 123-133, 1950.

LÉVY-BRUHL, H. L'ethnologie juridique: définition et histoire. In: POIRIER, Jean (dir.). Ethnologie générale. Paris: Gallimard, 1968, p. 1111-1179. (Encyclopédie de la Pléiade)

LÉVY-BRUHL, H. Les délits politiques. Recherche d'une définition. Revue Française de Sociologie, v. 5, n. 2, p. 131-139, 1964.

LÉVY-BRUHL, H. Sociologia do direito. Tradução Antonio de Pádua Danesi. São Paulo: Martins Fontes, 2000.

MASSELLA, A. B. A realidade social e moral do direito: uma perspectiva durkheimiana. Lua Nova, n. 93, p. 296-295, 2014.

ROULAND, N. Anthropologie juridique. Paris: Presses Universitaires de France, 1988.

ROULAND, N. L'anthropologie juridique. $2^{\mathrm{e}}$ édition. Paris: Presses Universitaires de France, 1995.

PUZHAEV, V. V. Henri Lévy-Bruhl's doctrine on law and on the formation of legal science of a new type. Journal of Foreign Legislation and Comparative Law, n. 4, p. 58-66, 2017.

SCHLUCHTER, W. La sociologie du droit comme théorie empirique de la validité. In: HEURTIN, J.-P; MOLFESSIS, N. (dir.). La sociologie du droit de Max Weber. Paris: Dalloz, 2006. p. 3-26.

SERVERIN, É. Sociologie du droit. Paris: La Découverte, 2000.

SOUBIRAN-PAILLET, F. Histoire du droit et sociologie: interrogations sur un vide disciplinaire. Genèses, n. 29, p. 141-163, 1997.

SOUBIRAN-PAILLET, F. Juristes et sociologues français d'après-guerre: une rencontre sans lendemain. Genèses, v. 41, n. 4, p. 125-142, Déc. 2000.

SOULA, M. Au-delà de l'histoire du droit. Retour sur la trajectoire d'un entrepreneur scientifique, Henri Lévy-Bruhl (1884-1964). Clio@ Thémis - Revue Electronique d'Histoire du Droit, n. 9, p. 1-13, 2015.

STEINER, P. La sociologie de Durkheim. Paris: La Découverte, 2005.

TERRÉ, F. La sociologie du droit de Durkheim. In: BOUDON, R. (dir.). Durkheim fut-il durkheimien? Actes du colloque organisé les 4 et 5 novembre 2008 par l'Académie des Sciences Morales et Politiques. Paris: Armand Colin, 2011. p. 127-143.

TREVES, R. Sociologia do direito: origens, pesquisas e problemas. Tradução Marcelo Branchini. 3. ed. Barueri: Manole, 2004. 
TREVIÑO, A. J. The sociology of law: classical and contemporary perspectives. New Brunswick, N.J.: Transaction Publishers, 2008.

VALADE, B. Durkheim: les idées directrices d'une sociologie scientifique. In: VALADE, B. (coord.). Durkheim: 1'institution de la sociologie. Paris: Presses Universitaires de France, 2008. p. 45-77.

VANDERLINDEN, J. Anthropologie juridique. Paris: Dalloz, 1996.

VAN HOUTTE, J. La sociologie du droit ou les limites d'une science. Droit et Société, n. 3, p. 171-186, 1986.

VILLAS BÔAS FILHO, O. A sociologia do direito: o contraste entre a obra de Émile Durkheim e a de Niklas Luhmann. Revista da Faculdade de Direito da USP, v. 105, p. 561593, jan./dez. 2010.

VILLAS BÔAS FILHO, O. A juridicização e a judiciarização enfocadas a partir da "sociologia política do direito" de Jacques Commaille. Revista Brasileira de Sociologia do Direito, v. 2, n. 2, p. 56-75, jul./dez. 2015.

VILLAS BÔAS FILHO, O. Émile Durkheim. In: CAMPILONGO, C. F.; GONZAGA, A. A.; FREIRE, A. L. (coord.). Enciclopédia jurídica da PUC-SP. Tomo 1: Teoria Geral e Filosofia do Direito. São Paulo: Pontifícia Universidade Católica de São Paulo, 2017a. Disponível em: https://enciclopediajuridica.pucsp.br/verbete/140/edicao-1/emile-durkheim. Acesso em: 15 jul. 2019.

VILLAS BÔAS FILHO, O. Émile Durkheim e a análise sociológica do direito: a atualidade e os limites de um clássico. Revista Eletrônica Direito e Sociedade, v. 5, n. 2, p. 229-250, $2017 b$.

VILLAS BÔAS FILHO, O. O desenvolvimento dos estudos sociojurídicos: da cacofonia à construção de um campo de pesquisa interdisciplinar. Revista da Faculdade de Direito da USP, v. 113, p. 251-292, jan./dez. 2018.

VILLAS BÔAS FILHO, O. Desafios da pesquisa interdisciplinar: as ciências sociais como instrumentos de "vigilância epistemológica" no campo dos estudos sociojurídicos. Revista Estudos Institucionais, v. 5, n. 2, p. 530-558, 2019a.

VILLAS BÔAS FILHO, O. Direito e sociedade na obra de Émile Durkheim: bases de uma matriz sociológica para os estudos sociojurídicos. São Paulo: Editora Mackenzie, 2019b.

VILLAS BÔAS FILHO, O. Uma abordagem sociológica do pluralismo jurídico: a "teoria da polissistemia simultânea” de André-Jean Arnaud. Quaestio Iuris, v. 12, n. 2, p. 522-556, 2019c. 